\title{
La teoría de los modelos de mundo a la luz de Heidegger, Lacan y McCarthy
}

\author{
Manuel Asensi Pérez ${ }^{\bullet}$ \\ Universitat de València-Estudi General
}

\begin{abstract}
Resumen
Con el fin de proseguir un análisis de la noción de «modelo de mundo» tal y como fue expuesta en el modelo teórico de la así llamada «Crítica como sabotaje» (2011), este texto lleva a cabo una lectura de la noción de mundo en Heidegger según la modalidad y los términos de la misma crítica como sabotaje. Más allá de lo que sean las «intenciones» de Heidegger en su reflexión sobre la relación entre ser y lenguaje, este ensayo subraya cómo el concepto de "precomprensión" está en la línea de lo que llamamos capacidad modalizadora de los discursos. Esa aproximación a Heidegger se ve acompañada por las referencias de Lacan y de Marx, y es ilustrada a partir de la novela de Cormac McCarthy No Country for Old Men.
\end{abstract}

\section{Palabras clave:}

Teoría de los modelos de mundo · Crítica como sabotaje Heidegger · Lacan · McCarthy

\begin{abstract}
The aim of this text is to continue the analysis of the notion of «model of the world» as developed in the theoretical model of the so called «criticism as sabotage» (2011). Considering the importance of Heidegger's notion of the world, we read it according to the terms of criticism as sabotage itself. Beyond Heidegger's «intentions» in his thought on the relationship between being and language, we highlight how the concept of "pre-understanding» has to do with what we call discourses' modelling capacity. This approach to Heidegger comes along with Lacan's and Marx's references, and it is illustrated with Cormac McCarthy's novel No Country for Old Men.
\end{abstract}

\section{Key words:}

\footnotetext{
- Theory of models of the world · Criticism as sabotage Heidegger · Lacan · McCarthy
} 


\section{Delimitación de los objetivos}

De Don Quijote, recordando los libros de caballería para decidir qué camino tomar cuando se halla ante una encrucijada, a Petrarca que, en vez de mirar desde la cumbre del Mont Ventoux el panorama lejano consulta las confesiones de San Agustín, hallamos antes y después una insistencia en el carácter modelizador de los discursos como forma de aproximación al mundo. Uno de los ejes centrales de la crítica como sabotaje es que todo discurso, desde el nivel oracional hasta el del texto, presenta un modelo de mundo que posee una capacidad modelizadora ${ }^{1}$. Aunque tanto en las investigaciones fundacionales de esta teoría (Asensi, 2011) como en los trabajos posteriores dedicados a ella en diferentes campos (Vàzquez, 2013; Ferrús y Zabalgoitia, 2013; Ferrús y Poch, 2014; Atutxa, 2014; Méndez, 2015) es una noción usada de forma profusa, se hace necesario darle una mayor fundamentación, especialmente en lo que se refiere a la noción de «mundo».

Este trabajo está dedicado precisamente a ello y busca indagar en el significado de los dos términos que componen la expresión «modelo de mundo». Con ese fin tomaremos el hilo conductor de la reflexión heideggeriana en Sein und Zeit (1927), acompañada por Lacan, y emplearemos la novela de Cormac McCarthy No Country for Old Men (2005) como forma de ilustrarla.

Una de las reflexiones más agudas sobre la noción de «mundo»es, sin duda, la que llevó a cabo Heidegger en la obra mencionada. La elección de este autor se hace porque en su tratamiento del «mundo» condensa muchas otras aproximaciones de la tradición filosófica (por ejemplo, la de Descartes). No pretendo seguirlo simplemente para saber qué tiene que decirnos acerca del «mundo», sino para entresacar de ello aquellos caracteres que nos permitan caracterizar el objeto de nuestra reflexión.

\section{La unidad del sujeto y del mundo}

El primer paso de su aproximación consiste en afirmar el carácter unitario del ser y el mundo, tal y como pone de relieve la escritura conjunta de la expresión «ser-en-el-mundo». Ahora bien, Heidegger se precipita de inmediato a deshacer una posible confusión: ese "estar dentro» no debe comprenderse a la manera de una cosa que está dentro de la otra, como por ejemplo el agua que se halla dentro de un vaso. Al pensarlo de esta manera nos representamos al agua y el vaso como categorías con una identidad propia independiente que en un momento determinado han coincidido en ese "estar dentro» la una de la otra. La precisión es clara: no es que los hombres y las mujeres estén a priori ahí, y de repente vayan al mundo, igual que una mesa está en un aula durante un tiempo determinado, sino que el «estar-en-el-mundo» es una estructura esencial del sujeto (del Dasein). 
Dicho de otro modo: la facticidad del ente que está en el mundo significa una ligazón entre uno y otro en el sentido de que el ser intramundano se refiere a una necesaria espacialidad existencial. No se puede decidir estar en el mundo o no estar en él, en todo caso se podría estar en un mundo y no en otro. Cuando Fray Luis de León escribe en su "Oda a la vida retirada»: "iQué descansada vida/la del que huye del mundanal ruido,/y sigue la escondida/senda, por donde han ido/ los pocos sabios que en el mundo han sido...!», hay que tener en cuenta que se huye de un mundo, el que está lleno de ruido, pero no del mundo, puesto que esa "escondida senda" a la que se refiere no es menos mundo que el otro.

De hecho, Fray Luis expresa esto mismo cuando menciona a esos "pocos sabios que en el mundo han sido». Éstos se van de un mundo a otro, pero no se apartan del mundo, porque estar en el mundo es una característica existencial.

El Dasein no es "próximamente» una entidad que es, por decirlo así, libre de Estar-en [el mundo], al que de vez en cuando le viniera en ganas establecer una «relación» con el mundo. Ese relacionarse con el mundo no es posible sino porque el Dasein, en cuanto estar-en-elmundo, es como es. (Heidegger, II-12-57.Traducción modificada por mí) ${ }^{2}$

Así, pues, tenemos ya una primera característica del mundo: éste es un rasgo existencial del sujeto, no es posible el sujeto sin el mundo, se trata de una relación de reciprocidad ontológica.

Esa atadura entre el sujeto y el mundo se determina por un hecho contundente: la relación del sujeto con las cosas que le rodean, con los útiles $(Z e u g) .{ }^{3}$ Heidegger recuerda el término griego $\pi \rho \alpha \gamma \mu \alpha \tau \alpha$, pero recordando que el sujeto no se relaciona con meras cosas, sino con útiles que sirven para algo. Este «algo para...» subraya que no es posible pensar los útiles sino como remisión hacia algo, como una referencia de algo hacia algo. El rifle de calibre 270 que maneja Llewelyn Moss en No Country for Old Men, no es sólo una cosa, sino un útil que remite a la caza de antílopes. Es por ello que Heidegger habla del «contribuir a la empleabilidad, la manejabilidad» como constitución de la totalidad de útiles (Zeuggganzheit) (Rivera, 2003:91).

Por esa razón, los útiles que sirven para algo están a la mano con vistas a su empleabilidad. Pero esa remisión no se limita a otra cosa, no es solo una acción con vistas a conseguir algo, sino que remite al portador, al usuario, al propio sujeto: "Con la obra no comparecen tan solo entes a la mano, sino también entes que tienen el modo de ser del hombre» (93). Por ello, podemos decir que un mundo está compuesto por unos sujetos que llevan a cabo acciones mediante determinados útiles que, entre otras cosas, dan su lugar a tales sujetos.

Quiere decirse que no es posible comprender el mundo sino a partir de esa relacionalidad del sujeto con los útiles que remiten a otra cosa, y entre ellas al ente que es el mismo sujeto. En el mundo circundante de Llewelyn Moss, el rifle remite a los antílopes y a él mismo como sujeto de una acción. Tenemos, pues, una segunda característica aproximativa del mundo: la relación existencial entre el sujeto y unos útiles que remiten a otras cosas y al mismo sujeto. Dada la índole del planteamiento heideggeriano, el problema del valor económico de los útiles, que tan importante es en el caso de la novela de McCarthy, queda al margen. No cabe duda de que uno de las remisiones esenciales de los útiles, desde las formaciones del capitalismo, es el dinero, a la vez que el dinero es otro útil cuya característica esencial es el remitir bien al dinero mismo, bien a otros útiles. Se trata naturalmente 
del valor de mercancía de dichos útiles, en el sentido marxista. Por ello, habría que añadir que si el mundo está compuesto por unos sujetos que llevan a cabo acciones mediante determinados útiles, debe tenerse en cuenta que tales acciones implican la conversión de los útiles en mercancías.

\section{3. Útil, mercancía y fetichismo}

De hecho, Marx también habla de los útiles, pero para señalar que la «utilidad de los objetos no flota en el aire» (Marx, 1885:4). Podría decirse que el tratamiento que Heidegger hace de los útiles, en razón de su estrategia narrativa ${ }^{4}$, queda flotando en el aire porque al marcar la diferencia ontológica entre ser y ente se impide a sí mismo vislumbrar la dimensión material de los entes que son los útiles. Si se desea analizar de manera precisa la noción de mundo, se vuelve imperativo verlo tanto desde la perspectiva del ser como desde la materialidad de los entes y en este sentido el análisis marxista es mucho más certero, aunque se pierda la otra dimensión del problema. Si los útiles son fundamentales para comprender la noción de mundo, no podemos dejar de ver el útil desde el punto de vista de su calidad y de su cantidad, desde su valor de uso (en el que se detiene Heidegger) y desde su valor de cambio (que Marx analiza de forma especial). Cuando Heidegger dice de los útiles que sirven para algo, nombra justo el valor de uso de los mismos, y deja de lado el problema de su valor de cambio.

La inseparabilidad del ser y el mundo, tal y como la muestra Heidegger, sirve ahora para darse cuenta de que ello se refiere también a la dependencia del sujeto respecto al útil en tanto mercancía. Si se sigue de cerca el análisis que Marx hace de la mercancía, se observa que no sólo es que las mercancías mantengan una relación de equivalencia entre sí (el cambio de unos valores de uso por otra clase de valores de uso), o que sean un producto del trabajo humano, sino también que una de esas equivalencias o remisiones esenciales es el dinero, lo que Marx nombra como «mercancía-dinero»: «Esta mercancía tiene como función social especifica, y por tanto como monopolio social dentro del mundo de las mercancías, el desempeñar el papel de equivalente general» (Marx, 1885:35, la cursiva es del autor). De este modo, al afrontar el problema de la remisión de los útiles, como una de las características básicas del mundo, debe tenerse en cuenta esa equivalencia entre los útiles (mercancías) y el dinero, y viceversa.

Al mismo tiempo, la ligazón entre el sujeto y las mercancías se ubica en otro nivel dado que, digámoslo así, el sujeto tiene antojos en relación a las mercancías. Si no se tiene en mente este hecho, difícilmente se percibirá que nos encontramos ante el problema del fetichismo: el carácter social del trabajo pasa por ser una propiedad natural de los objetos (37).

Es ahí donde reside el impulso del sujeto en relación a las mercancías. Cierto que la camioneta de Moss es un útil que le permite ir de un lado a otro, y en ese sentido la remisión es clara, pero igualmente cierto es que esa camioneta le ha permitido llegar al lugar donde halla el motivo de su codicia y anhelo: un maletín lleno de fajos de diez mil dólares. 
El par heroína-dólares representa para Moss y para todos aquellos interesados en dicho par, la posibilidad de acceder a una riqueza de útiles, necesarios e innecesarios, que los convierte en sujetos socialmente privilegiados. Chigurh es un mercenario que desde el inicio de la novela va matando a quien se le pone por delante, y desde el inicio de la novela la voz que guía el silogismo de ese texto de McCarthy ubica el núcleo del mal, ese «living prophet of destruction». Sin embargo, la orientación general de las acciones del texto cambia en el momento en que Moss halla el maletín de piel lleno de dinero. Todo parte de él y todo confluye en él. Sin advertir el anhelo fetichista de Moss y de todos aquellos que andan tras dicho maletín, no se puede comprender bien el modelo de mundo que presenta No Country for Old Men, ni tampoco lo que en términos generales significa «mundo» en la expresión «modelo de mundo».

\section{El mundo y los mundos}

Muy pronto Heidegger deja entrever la imposibilidad de hablar del mundo en singular, puesto que está el mundo privado, el mundo público, el circundante, etc. Resulta más acertado tratar el mundo en términos de «mundos», hablar no tanto de «modelos de mundo» como de «modelos de mundos». Pero antes de llegar a esta cuestión, conviene detenerse en un paso crucial que da Heidegger del que se podrán inferir una serie de conclusiones que nos llevarán más allá de sus propios argumentos.

En el inicio del parágrafo 16, al hacer la pregunta fundamental "¿Cómo "hay" mundo?» responde: «Si el Dasein está ónticamente constituido por el estar-en-elmundo y a su ser le pertenece no menos esencialmente una comprensión del ser de su propio sí-mismo por indeterminada que ella sea, ¿̨no tendrá también una comprensión del mundo?» (Rivera, 2003: 94. Trad. ligeramente modificada). Sin esa comprensión no sería posible hacer la distinción entre lo que está a la mano en tanto útil, lo que está a la mano en tanto no útil, y lo que falta. Pero ¿̇cómo sería posible esa comprensión sin que el sujeto tuviera una estructura imaginaria y discursiva en torno a su mundo? ¿Cómo sería posible sin que tuviera, en tanto constitutivo, un modelo de «su»mundo? No hay otra forma de entender la afirmación heideggeriana según la que "El mundo es, por consiguiente, algo "en lo que" el Dasein en cuanto ente ya siempre ha estado, y a lo que en todo explícito ir hacia él no hace más que volver» (97. La cursiva es del autor). Ese «haber estado», ese «volver» indica una repetición que, como más adelante veremos, supone un discurso previo y ya formado que abre y cierra el horizonte de la cotidianeidad y del mundo.

Llama la atención que Heidegger, tras analizar lo que supone el no útil en tanto condición que saca a la luz el «mero-estar-ahí», se dirija inmediatamente en el siguiente parágrafo a tratar el problema de la remisión y del signo. ¿De qué puede ser síntoma esa necesidad de tratar el problema del signo? Naturalmente del vínculo entre la comprensión y el modelo de mundo en tanto discurso. Sin embargo, en este capítulo sobre el signo, apoyado en su maestro Husserl, Heidegger se preocupa más por determinar la remisión de los útiles más que del lenguaje. Lo que toma como objeto de análisis son «los indicios, los presagios, las trazas, las marcas, los signos distintivos...» (99). La distinción que hace entre la remisión como utilidad 
(el rifle de Moss sirve para matar antílopes) y la remisión como señal (cuando Moss oye "the key in the lock», 304) $)^{5}$ permite, como indica Heidegger, encontrarse con los entes a la mano.

Sin embargo, todo su análisis se limita al ámbito de lo útil (como signo), constitutivo de la mundaneidad. No se trata aún del lenguaje, del enunciado o del discurso. De hecho, el mundo no puede entenderse de forma adecuada sin este carácter de remisión de los signos (de los útiles), en tanto estos forman una totalidad dando lugar a «un contexto remisional» (103), y en tanto se hacen accesible al «cuidado» del sujeto (a la circunspección, dice Heidegger). Sin embargo, pronto se aprecia que esa remisión carece de sentido sin la presencia del lenguaje y del discurso.

Es en el siguiente parágrafo cuando ofrece una definición directa de lo que el mundo es, definición de la que habrá que partir para el desarrollo posterior de esa idea. Hela aquí:

El en-qué [«wherein», traducen Macquarrie y Robinson el «Worin» del texto alemán] de un acto de comprensión que se refiere a sí mismo, es lo que da lugar al encuentro con los entes que tienen el modo de ser de la condición respectiva; y ese «en-qué» [Worin»] es el fenómeno del mundo. (Mi traducción) (la cursiva es del autor) ${ }^{6}$

El «sichverweisenden Verstehens» implica la reflexividad del comprender (la auto-remisión de la comprensión más exactamente), y tanto la traducción española como la inglesa así lo ponen de manifiesto. La inglesa dice: "The "wherein" of an act of understanding which assigns or refers itself...» (Macquarrie y Robinson, 1969:119), donde el «itself» deja claro que su antecedente es el «act of understanding». La española, por su parte, escribe: «El en-qué del comprender que se autorremite» (Rivera, 2003:108), frase en la que el «se» alude al «en-qué del comprender». Del mismo modo en el texto alemán: «Das Worin des sichverweisenden Verstehens...», el «sich» apunta hacia el «verweisenden Verstehens». Sin embargo, no resulta difícil advertir que tal acto de comprensión implica en rigor al Dasein, del que unas líneas antes había manifestado lo siguiente: «el Dasein se da previamente a entender a sí mismo su estar-en-el-mundo» (Rivera, 2003:108).

La conclusión a la que se puede llegar, teniendo en cuenta el desarrollo argumental de Heidegger, es que el mundo resulta irrepresentable sin la comprensión del Dasein cuya significación establece su relación con los útiles. Por consiguiente, en el lenguaje de la teoría de los modelos de mundo diríamos que no hay mundo sin el modelo que lo configura, entendiendo por modelo esa comprensión de la que habla Heidegger que no puede ser otra cosa más que discurso. Que el mundo no es sino un modelo de mundo fosilizado es lo que Heidegger trata de decir cuando habla de la familiaridad que el Dasein tiene con la significatividad, la cual representa nada más y nada menos la condición óntica del descubrimiento de la totalidad respeccional de los útiles.

Marx se equivoca cuando ve en el lenguaje únicamente algo que «nace, como la conciencia, de la necesidad, de los apremios del intercambio con los demás hombres» (Marx y Engels, 1970:31), puesto que la comprensión del intercambio debe preceder al intercambio mismo, sin el cual éste no existiría. Cuando en el prólogo de La ideología alemana, dicen en el tono que les caracteriza: «Liberémoslos de los fantasmas cerebrales, de la ideas, de los dogmas, de los seres imaginarios, bajo cuyo yugo degeneran», en realidad están diciendo que es necesario liberarse 
de los modelos de mundo que han derivado en explicaciones y en acciones totalmente gratuitas. Y al afirmar «rebelémonos contra esa tiranía de los pensamientos. Ensenémoslos a sustituir estas quimeras por pensamientos que corresponden a la esencia del hombre», ponen el dedo en el centro de la cuestión: la necesidad de acabar con un modelo de mundo quimérico y sustituirlo por otro.

El problema es que Marx se empeńa en acabar con los modelos de mundo para enfrentarse a la realidad material de la forma más directa posible. Al plantearse el problema del lenguaje y del pensamiento en esos términos, se sitúa en esa línea cartesiana en la que se asegura que no hay nada "que esté enteramente en nuestro poder sino nuestros propios pensamientos» (Descartes, 1637:45). Cuando ańos después, Althusser trató el problema de la ideología no incurrió en ese error, desde el momento en que reconoció que la salida de la ideología planteaba un problema. Al definirla como «la representación de la relación imaginaria de los individuos con sus condiciones reales de existencia» (1969:144), establecía la forma en que acción y modelo de mundo están en una relación de coimplicación en la que el modelo tiene que preceder necesariamente al acto.

\section{El mundo, el significante y la mediación}

Cuando Moss descubre el maletín de piel que tenía en su poder el muerto («There was a heavy leather document case standing upright alongside the dead man's knee and Moss absolutely knew what was in the case and he was scared in a way he didn't even understand» [48]), ese mundo violento ante el que se encuentra pertenece a un modelo de mundo previo en el que los sujetos matan por dinero, y en el que ese útil-objeto que es el «leather document case» forma parte de una totalidad relacional en la que intervienen las camionetas abandonadas, los cadáveres, las armas, la soledad, y todo lo que el dinero puede. Lo prueba las palabras del narrador: «He didn't know what it added up to but he had a pretty good idea. He sat there looking at it and then closed the flap and sat with his head down. His whole life was sitting there in front of him» (49-50). No solo es lo que ve (mediado y posibilitado por lo que ya sabe), es lo que imagina que ha pasado; es todo lo que los miles de dólares de que está lleno el maletín prometen en un modelo de mundo gobernado por el dinero desmitificante; $y$, por supuesto, es el miedo.

Sin el discurso, sin los significantes previos que ordenan ese horror no habría mundo. En el contexto de su crítica a la fenomenología, Heidegger ya niega que se pueda acceder a los fenómenos a partir de una "visión" fortuita, "inmediata" e impensada» (Rivera, 2003:56). ${ }^{7}$ Por ello, dirá más adelante que «el comprender en su carácter proyectivo constituye existencialmente la visión (Sicht) del Dasein» (165). Es justo en este punto cuando se hace patente lo que decíamos unas líneas más arriba: al hablar de los útiles y del problema semiótico de la remisión, es necesario tener en cuenta que los útiles no pueden entenderse de forma plena sino en relación a la cuestión de la mercancía y del valor. No en vano el epicentro de la 
novela No Country for Old Men es el descubrimiento de esa «leather document case» repleta de dinero, cuya remisión es a todo un campo de riqueza de pertenencias y de útiles que pueden sacar a Moss de la pobreza.

La distinción lacaniana entre la mirada y la visión plantea asimismo que mientras la mirada (en tanto significante) organiza la visión, ésta solo es posible en función de la delimitación que establece la primera. Por eso escribe que «en el campo escópico la mirada está afuera, soy mirado, es decir, soy cuadro. Esta función se encuentra en lo más íntimo de la institución del sujeto en lo visible» (Lacan, 1995 [1973]:113). Si la mirada no estableciese el límite desde fuera, entonces aparecería lo real y podríamos verlo todo, o lo que es lo mismo, tendríamos una alucinación. Estas dos aproximaciones, la de Heidegger y la de Lacan, ponen de relieve que la relación del sujeto con el mundo fenoménico está mediatizada por lo que uno llama "comprensión», el otro «mirada», y aquí llamamos «modelo».

Ahora bien, para seguir con nuestra indagación de la expresión modelo de «mundo», y tras explicar la relacionalidad y la remisión como una de las características fundamentales del mundo, conviene dirigirse al tratamiento que Heidegger hace de la Gerede («habladuría», «idle talk», según las traducciones que manejamos). Podría pensarse que se trata de un fenómeno negativo, pero en realidad aclara que constituye «el modo de ser del comprender y de la interpretación del Dasein cotidiano. Ordinariamente el discurso se expresa y ya se ha expresado siempre en palabras» (Rivera, 2003:186). Estas palabras son muy importantes para la comprensión de la idea de que el mundo ya es un modelo de mundo naturalizado y hecho historia y proyecto. Si ya ha quedado claro que sin comprensión no hay forma de relacionarse con la acción y con los objetos, ello supone que no puede haber mundo separado de un modelo de mundo.

Heidegger insiste: «El haber sido dicho, el dictum, la expresión, garantiza la autenticidad del habla [the genuineness of the discourse, dice la traducción inglesa] y de su comprensión, así como su conformidad con las cosas» (187). Interesa más la traducción «discurso» del inglés porque de eso de trata en la teoría de los modelos de mundo. No obstante, esta afirmación de Heidegger tiene un problema. Si con autenticidad o con genuineness se refiere a lo propio del discurso en tanto repetición, está en lo cierto, pero si como demuestra al final de la cita alude a la relación con las cosas, entonces Heidegger olvida el carácter deformante de todo signo, sea del tipo que sea. Carácter que implica una gradación en cuanto al acercamiento del signo a la cosa, en cuyo extremo se halla la mentira.

Es cierto que reconoce que la repetición acrecienta la falta de fundamento del discurso, y que no hace falta tener la intención de engañar a nadie de forma voluntaria. Pero no es menos adecuado decir que aunque la habladuría siempre sea una obstrucción, ésta puede ser doble. Una pertenecería a la dimensión del impersonal «se dice», del uno. Otra pertenecería a la obstrucción que engaña y duele, aunque ese engaño no caiga dentro del campo de la conciencia.

De cualquier forma, no nos precipitemos, a fin de cuentas nos movemos en niveles diferentes: Heidegger habla de la condición ontológica del Dasein y de su estar-en-el-mundo. Y ello nos sirve para comprender el por qué la noción de modelo de mundo no puede ser netamente separada del mundo, que es en definitiva uno de los objetivos que aquí se persiguen. Por eso, compartimos esta afirmación contundente de Heidegger: «No hay nunca un Dasein que, intocado e incontaminado por este estado interpretativo, quede puesto frente a la tierra 
virgen de un «mundo» en sí, para solamente contemplar lo que le sale al paso» (188). Todos los sujetos parten de, tienen, comparten, o se pelean a partir de un modelo de mundo. No hay ni ha habido mundo de la Arcadia en la que los fenómenos se revelen en sí mismos y de forma primeriza, no hay «luces o aceros aún no usados» (según el verso de Vicente Aleixandre), pues esa visión se halla mediada por un modelo de mundo. La distinción entre un mundo contaminado y otro incontaminado queda obsoleta desde este punto de vista.

\section{El Mundo y el espacio}

En el mundo, tal y como lo estamos revelando aquí al hilo de Heidegger, la presencia del conflicto resulta fundamental tanto en la relación con los otros, como en el plano de la lucha de grupos y clases sociales. Lo anunciamos más arriba: Heidegger no presta atención a esta dimensión clave del mundo, pero es pertinente indicar que en el mundo la raíz del conflicto no está separada de la solidaridad entre sujeto y útil, tal y como quedó claro al tratar el vínculo entre útil y mercancía. Desde el momento en que se considera el valor de mercancía, de valor y de plusvalía, de los útiles, se vuelve nítida la razón del conflicto entre modelos de mundo y acciones. De entrada sería imposible pensar el mundo y su estructura relacional sin tener en cuenta que el sujeto ocupa un tiempo y un espacio, pues la remisión de lo que Heidegger denomina Zeug (útil) no puede sino tener lugar en un momento y en un lugar, en el contexto de una dinámica de la mercancía y del fetichismo.

Si en el punto de partida, el estar-en-el-mundo no es comprendido como un estar una cosa dentro de otra (el agua dentro del vaso, decíamos), parece lógico que Heidegger haga la crítica de la noción cartesiana de espacio como res extensa (en tanto correlato de una res cogitans). Tal crítica la dirige contra la concepción sustancial tanto de la naturaleza como del sujeto. En efecto, Descartes se encuentra ante la necesidad de aclarar si hay algo que esté separado de mí, algo que pueda diferenciarse del pensamiento. Aunque los sentidos no puedan darme la clave de lo que sean las cosas en virtud de su movilidad, bien puedo llegar a la conclusión de que eso que está fuera de mí es algo "extenso, flexible y mudable» (Descartes, 1641:103). Esa sustancialidad pone de relieve el hecho de que el sujeto se enfrenta a una res extensa como prueba de lo que él es.

Aunque quede claro que el espacio es constitutivo del mundo, dicho espacio no es lo previamente dado, sino aquello en lo que tiene lugar el modelo de mundo que ordena la respeccionalidad de los útiles y de los entornos propios. Como pone de manifiesto Heidegger «la específica espacialidad del ente que comparece en el mundo circundante, se funda en la mundaneidad del mundo, en vez de ser el mundo en que está-ahí en el espacio» (Rivera, 2003:122). Precisamente por ese estar a la mano de los útiles queda implicado el espacio y la noción de modelo como ordenamiento de las relaciones: «la cercanía direccionada del útil significa que éste no tiene simplemente su lugar en el espacio como un ente que está-ahí en alguna parte, sino que en cuanto útil está por esencia colocado, instalado, emplazado, puesto» (123). 
Del mismo modo, la espacialidad del sujeto (del Dasein) ${ }^{8}$ tampoco es un estar dentro de un espacio natural, urbano o cósmico. Se trata de una espacialidad en tanto Ent-fernung («des-alejación», "de-severance») y Ausrichtung («direccionalidad», "directionality»), lo que quiere decir que el Dasein hace desaparecer la lejanía, lleva a cabo un acercamiento, y en consecuencia va en la dirección de la cercanía. Que el Dasein tenga "una tendencia natural a la cercanía» explica no solo el conocimiento de las ciencias de la naturaleza, sino la tecnología misma (el teléfono, el email, el whatsapp, etc.).

Adviértase que hay aquí una vertiente que completa lo dicho anteriormente acerca de que el mundo tiene la característica de un sujeto relacionado con el útil que remite a otra cosa, dado que esa relación está espacialmente mediada por un intento de acercarse y tener a la mano los útiles. Por esa causa, Heidegger ubica en ese fenómeno «el ser-en-si del verdadero mundo» (127).

En la novela de McCarthy (tratándola no como novela sino como mundo) puede apreciarse este hecho. En el momento que Chigurh se encuentra ante la camioneta de Moss le pide al conductor que se detenga allí: «Pull up here. Have you got a screwdriver?» (163-164, 80). El destornillador lo emplea para arrancar la placa de la matrícula con el objetivo de iniciar la búsqueda de Moss. ¿Qué es, pues, el espacio del mundo? No es una simple topografía de determinadas características (el desierto, de hecho), sino el movimiento en virtud del cual alguien (Chigurh) va en la dirección de desalejar a Moss y el maletín de dinero que se ha llevado. Puede ser un objeto, una persona o un animal (por ejemplo, la ballena en Moby-Dick).

Cuando Bajtin emplea la noción de "cronotopo" para referirse a la íntima conexión entre el tiempo y el espacio en la literatura (Bajtín, 1989 [1975]: 237 y ss.), no se interroga en absoluto a propósito de la noción de «espacio», lo emplea de forma acrítica como categoría estética, sin analizar de qué puedan ser trasuntos el espacio y el tiempo. Aquí, no obstante, el espacio en cuanto elemento constitutivo del mundo no es pensado como un continente o una res extensa, sino como una forma de estar el sujeto en el mundo. Habría que reconocer que cuando la narratología trató el actante sujeto en función del objeto que persigue (Greimas, 1966), estaba a su manera dando en el clavo, dado que, aun con criterios formales, señalaba las dos características fundamentales del espacio, la des-alejación y la direccionalidad.

Es Heidegger quien trata esta dimensión de una forma más profunda, dado que establece el vínculo entre ser espacial y des-alejación. Sin embargo, habría que añadir que si dicha des-alejación determina el espacio, también el alejamiento como huida lo determina igualmente. Hay momentos en que la direccionalidad no pretende acercarse a algo o a alguien, sino justamente lo opuesto, alejarse (fernung) por miedo u otro motivo.

Moss no solo intenta des-alejar el antílope que está a una determinada distancia, sino que también pretende alejarse de aquel que le persigue (Chigurh) en el instante en que éste le encuentra: «Moss didn't stop. He pushed out through the front door and down the steps. By the time he'd crossed the Street Chigurh was already on the balcony of the hotel above him» (312). Si el espacio está determinado por el des-alejamiento, también lo está por el alejamiento, por la direccionalidad en sentido contrario. Y que Heidegger no tematice este hecho sorprende por cuanto en el epígrafe 30 afronta el fenómeno del miedo (Furcht). Allí pone de relieve que ello se manifiesta cuando lo que comparece resulta amenazante, cuando ese algo puede afectarte. En ese caso, resulta inquietante, es dañino y está cercano (Rivera, 
2003:159-160). Prueba de ello es que cuando en el epígrafe 40 afronta el fenómeno de la angustia, lo hace a partir de dos premisas. Por una parte, en tanto huida del Dasein ante sí mismo y en relación a sí mismo, y no respecto a una amenaza de un hecho o un sujeto del mundo. Por otra parte, como una experiencia que no tiene su causa en un ente intramundano, sino que es indeterminado. Es el mismo hecho de estar-en-el-mundo lo que desata al angustia del Dasein. De cualquier modo, esta caracterización de la angustia como huida ya no se desarrolla en el marco de su reflexión explícita sobre el espacio.

Todas esas características del miedo, en tanto presentes en la precomprensión, hacen por ejemplo que Moss vaya en la direccionalidad de un alejamiento. Por ello diremos que el espacio del mundo no es comprensible al margen de una direccionalidad que puede adoptar la forma de un des-alejamiento o alejamiento, mezclados con ciertas formas intermedias relacionadas con los tres tiempos de la pulsión señalados por Lacan (1999 [1998]:201-206). El íntimo vínculo entre modelo de mundo y afecto es una característica fundamental del (modelo de) mundo, hasta el extremo de establecer lo que Heidegger denomina la aperturidad originaria del sujeto en el mundo. Y donde ello se pone de relieve en su máxima potencia es en el campo artístico.

¿Cómo sería posible separar el mundo de Llewelyn Moss del miedo que siente? Más arriba se han citado esas palabras del narrador en las que describe cómo sin abrir el maletín, cuyo contenido adivina, siente un miedo desconocido para él ("he was scared in a way he didn't even understand»). Heidegger lo hace notar del siguiente modo: «La comprensión tiene siempre su estado afectivo» (mi traducción) (Heidegger, 31-143). De ahí que plantee como necesario distinguir entre el comprender y el explicar. Lo cual permite a la vez apreciar la diferencia entre una dimensión conceptual y la afectiva, en el bien entendido de que nunca están netamente separadas, ni en el caso del (modelo de) mundo, ni en los modelos de mundo discursivos. De ahí que en la teoría de los modelos de mundo, cuando se trata de describir las modalidades semióticas de la «literature» o el «arte», se emplee el neologismo «afepto».

El matiz que introduce Heidegger es que la comprensión antecede a la explicación, pues ésta no es sino «la elaboración de las posibilidades proyectadas en el comprender» (Rivera, 2003:165), de ahí que se interprete el mundo ya comprendido. Incluso reconoce que en realidad no es que la interpretación le dé sentido a una comprensión previa, porque ésta ya tiene, por decirlo en términos lacanianos, una estructura significante que la interpretación desarrolla y expone. Es por ello que es necesario establecer una distinción entre el modelo de mundo naturalizado en tanto base heredada del comprender, y el modelo de mundo naturalizado en tanto desarrollo de una explicación basada en la comprensión.

\section{Mundo y tiempo}

Al hablar del mundo se hace necesario introducir la dimensión temporal, y como se verá de inmediato ésta surge de la propia lógica del espacio. Téngase en cuenta que al ligar este espacio al des-alejamiento, el alejamiento y la direccionalidad, se puso de relieve que ello implicaba la anticipación de los hechos. Moss siente miedo no por algo que esté pasando en el presente, 
sino por algo que vendrá en el futuro, aquel maletín lleno de dinero abre unas expectativa de futuro inciertas donde la posibilidad de la muerte se hace patente. Por consiguiente, tanto el des-alejamiento como el alejamiento se hacen en función de una anticipación que, a la vez, determina el presente del estar-ahí, y el haber ya sido.

El vínculo entre espacio y tiempo lo advierte Heidegger del siguiente modo: «la temporeidad del estar-en-el-mundo que así sale a la luz, se muestra a la vez como fundamento de la específica espacialidad del Dasein» (Rivera, 2003:350). ¿Cómo sería posible la comprensión sin la apertura de un poder-ser? ¿Cómo separar el hecho de que Llewelyn "comprenda", o "pre-comprenda», el maletín que tiene ante sí, de las posibilidades que el contenido de ese maletín le abre? De hecho, ese contenido hace que anticipe todos los problemas que le va a acarrear. Sin conocer a Chigurh, su manera de comprender dicho maletín ya anticipa esa figura, esa maldad. Tenía la seguridad, dice la narración, de que «someone was going to come looking for the money» (26). No es extraño reconocer en ello que la comprensión implica la temporalidad, en este caso concreto el futuro. El sujeto, en el proceso de comprensión, es cada vez como puede llegar a ser, queda arrojado en esa posibilidad, de ahí que Heidegger hable del «anticiparse-a-sí» (352), algo que puede darse o no, pero que liga definitivamente la comprensión a la dimensión temporal.

Pero ¿cómo sería posible que Moss se anticipara al futuro si no fuera por el hecho de que él ya ha sido, ya ha tenido unas experiencias previas (Vietnam, la condición humana, etc.), que le permiten anticiparse a sí mismo en un hipotético futuro que al final dejará de ser hipotético puesto que acabará fácticamente muerto debido a su fascinación por el dinero? Que él sienta un miedo del que el narrador dice en estilo indirecto libre «in a way he didn't even understand», no sería posible sin que ya conociera el miedo ante determinadas situaciones. Quizá ese miedo en concreto nunca lo conoció, pero sabe que es miedo, un miedo ya experimentado. Lo que el narrador dice en realidad es que desconocía la forma en que tenía ese miedo, pero no el miedo.

De ahí que Heidegger nos diga que la comprensión se funda en el futuro, pero la disposición afectiva «se temporiza primariamente en el haber-sido» (355). Es por ello que tanto la comprensión como la afectividad forman parte del eje temporal. No tiene ninguna dificultad entender cómo esa afectividad puede tener la forma del miedo y de la angustia, tal y como han sido analizados más arriba, más aún si se piensa precisamente en el personaje de Moss que tiene miedo. Roquentin tiene angustia, Moss tiene miedo, al menos eso es lo que narra la novela de McCarthy. El miedo es la espera de un mal venidero (en oposición a esto, la esperanza es la espera de un bien venidero); la angustia es el encuentro con la nada del mundo: «la angustia se angustia por la nuda existencia en cuanto arrojada en la desazón» (358).

Queda claro, a este respecto, que al hablar del mundo, de los mundos, y de dos de sus fenómenos fundamentales como son el tiempo y el espacio, es necesario enmarcarlos dentro del tema de la relación del sujeto con su entorno, el de la comprensión (discurso) y el de la disposición afectiva. La primera aparece vinculada al futuro, la segunda al pasado. ¿Y al presente? El presente, dice Heidegger, queda puesto en evidencia por esa condición del Dasein que es la «caída». Es en este punto cuando vuelve a aparecer el discurso.

Primero bajo la forma de lo que antes se definió como habladuría, ambigüedad y curiosidad (el antojo del que habla Marx). Segundo, en relación al discurso mis- 
mo. Advirtamos que lo que lleva a Moss hasta el maletín es el hecho de descubrir súbitamente a través de los prismáticos unos hombres muertos y unas camionetas abandonadas. Ello suscita su curiosidad, la cual supone que "lo a la mano y lo que está-ahí comparezca en sí mismo y “en persona” en cuanto a su aspecto» (361). La curiosidad de Moss es lo que le lleva a acercarse al lugar de los hechos, de forma que lo que ha descubierto desde la lejanía comparece en su presente. Es en ese presente en el que descubre un hombre «slumped dead over the wheel» (16), los vehículos llenos de balas, los zumbidos de las moscas y el resto de los muertos. Aunque Heidegger diga que la curiosidad busca ver solo por ver y no para comprender, es claro que esa separación no puede ser tan nítida, dado que en los primeros capítulos la comprensión es la condición sin la cual no hay relación entre el sujeto y los útiles. Es claro que Heidegger habla de otro tipo de curiosidad, de aquella que tiene que ver con el mundo del corazón, de los murmullos y habladurías. Pero la curiosidad parece un concepto más amplio que la delimitación que él hace de dicho fenómeno.

De la relación del discurso con el tiempo da fe el hecho de que el discurso sea una línea, una sucesión de significantes que se van borrando y apareciendo, y también el que continuamente hable de procesos temporales. La pregunta que el dueño de la gasolinera le hace a Chigurh, «You all gettin any rain up your way?» (70) tiene dos características fundamentales: por un lado, en tanto conjunto significante es una línea en el tiempo; por otro, se refiere a procesos temporales (se pregunta acerca de si ha llovido allí donde él supone que viene). Estos dos rasgos tienen su razón de ser en que «el discurso es tempóreo en sí mismo, por cuanto todo discurrir que hable sobre..., de... y a... está fundado en la unidad extática de la temporeidad» (364).

Ahora bien, se percibirá que en la explicación heideggeriana de la temporalidad hay algo extraño. Si la disposición afectiva remite al pasado del haber-sido, y la comprensión al poder-ser de un futuro, parece que en la medida en que dicho poder-ser afronta un sentimiento como el miedo, la disposición afectiva se proyecta asimismo sobre el futuro. A la vez, la comprensión no podría fundarse primariamente en el futuro (por emplear las mismas palabras de Heidegger) sino fuera por una pre-comprensión previa situada en el pasado. Ahí se produce un cruce que muestra la inseparabilidad de los tres tiempos, y que lleva a Heidegger a distinguir ese «existenciario» de la concepción vulgar del tiempo en la que pasado, presente y futuro aparecen separados.

Pero ¿qué puede significar ese cruce desde el punto de vista del mundo? Para entenderlo bien hace falta tener en cuenta lo que el presente (de la caída) supone en esa relación entre el pasado y el futuro. Al haber tratado el fenómeno de la curiosidad en términos de lo que procura un poder-ver, se vio que la avidez por lo no visto, por lo nuevo, lleva la curiosidad a saltar fuera de ese estar a la espera debido a que se desasosiega por ir siempre más allá. Al no detenerse en el presente de lo visto, salta fuera de ese presente. Lo que late tras ese apartarse de lo que está presente no es sino su huida ante la condición de arrojado hacia la muerte. Es por ello que Heidegger establece en este punto el vínculo entre presente, pasado y futuro a partir de un «éxtasis» concebido como saltar fuera de los tres. En consecuencia escribe: «el futuro no es posterior al haber-sido, ni éste anterior al presente. La temporeidad se temporiza como futuro que está-siendo-sido y presentante» (365).

En el instante en que Moss se halla ante el maletín repleto de fajos de dólares, y siente miedo, el haber-sido, su experiencia previa, se ubica como condición del futuro, de lo que él «ve» como un futuro posible, y por eso el futuro no es posterior, 
dado que está proyectado previamente por el pasado. A la vez, lo que ve en su presente, el maletín, establece una atadura extática entre lo que está viendo, lo que ha visto y lo que verá. La curiosidad por lo que ese presente del maletín le puede dar en el futuro hace que salte fuera de ese presente y, asimismo, del futuro, porque a partir de ese momento se pone en un movimiento febril que adopta la forma de una huida.

\section{La cotidianeidad y el testimonio}

Antes de proseguir el análisis de los modelos de mundo, es necesario referirse a una dimensión del mundo que es la cotidianeidad. De hecho, la novela de McCarthy muestra un análisis de esa dimensión del mundo muy incisiva. Si, como dice Heidegger, la cotidianeidad es «aquel modo de existir en el que el Dasein se mantiene "todos los días" (384), no es extrańo que ello comporte un cierto aburrimiento y una cierta pesadez, ni que el sujeto trate de evitarlos «buscando nuevas distracciones para su dispersión en los quehaceres» (385), pues la monotonía, el hoy y el mañana así como ayer, le atrapan en un estado turbio.

En realidad, la historia que narra la novela de MacCarthy es la de un hombre que ha sido arrancado de su cotidianeidad, de un hombre para el que la cotidianeidad desaparece (Llewelyn Moss); y a la vez es la historia de un hombre que sigue su cotidianeidad psicópata sin querer apartarse ni un milímetro de ella. El «I have only one way to live», citado unas líneas más arriba, es una comprobación del hecho de que Chigurh es el neurótico obsesivo incapaz de apartar sus actos de su modelo de mundo.

Desde el momento en que Llewelyn se encuentra con el maletín repleto de fajos de dólares, se produce una peripecia en su sentido aristotélico, un cambio de orientación radical en su vida. Si ir a la caza de antílopes forma parte de esas distracciones que aligeran su cotidianeidad, su hoy igual que ayer, el maletín supone la salida y la pérdida de lo que hace todos los días. Abandona la casa y entra en una carrera por huir de sus perseguidores, una carrera que terminará trágicamente. Sin embargo, Chigurh no hace sino seguir una línea fija y molar desde el momento en que es introducido en la historia de la novela.

En realidad, el intento de matar a Llewelyn y de recuperar el dinero (algo secundario para él) no hace sino proseguir lo que venía haciendo todos los días. Si la policía lo detiene, se las ingenia para matar al policía y si necesita un coche que no sea el del policía muerto, mata al primero que se encuentra en la carretera. Llewelyn no es sino un punto más en la cadena de su cotidianeidad. En ese inicio, el lenguaje de McCarthy emplea de forma retórica la literalidad de las palabras con el fin de establecer un contraste entre el uso denotativo de las oraciones y las acciones descritas: «He kicked shut the door and he wrapped the throwrung in a wad about them. He was gurgling and bleeding from the mouth» (7). Solo cede a la fuerza retórica cuando describe la muerte del dueño del coche en la carretera: «the blood bubbled and ran down into his eyes carrying with it his slowly uncoupling world visible to see» (9).

Que no hay mundo, sino modelo de mundo fosilizado, es palpable en este ejemplo. La muerte del conductor como «hecho» del mundo no se presenta nunca en sí mismo. No es solo que se trate de un acontecimiento ficticio (a fin de cuentas es 
una «novella»), ni que el tiempo de los verbos sea el pasado, todo eso pertenece al campo de la obviedad. Al margen de que ese hecho haya sucedido fenoménicamente o no, incluso si se tratara de una noticia aparecida en un periódico como reflejo de lo que "acaba de pasar o pasó hace poco», el hecho está mediatizado antes y después por una comprensión de ese "hecho». Cuando la muerte del conductor sorprendido en la carretera es descrita como un "carrying with it his slowly uncoupling world visible to see», no cabe duda de que el narrador salta dentro de la experiencia de quien está muriendo para mostrarla y narrarla.

El sujeto es visto como alguien al que el mundo visible se le "desgaja» (trad. esp., p. 13), quedándose ahí el mundo y él yéndose. La sangre en los ojos es el parapeto que separa al sujeto del mundo visible. Daría lo mismo que se tratara de una fotografía, tal y como ocurre en esas fotos en las que se muestra un cadáver de alguien asesinado. El fotógrafo "enmarca», acerca o aproxima, filtra el color, da al proceso de edición, lo que está fuera de él hasta el punto de que parece entregarte lo que, en realidad, está muy lejos, en ese campo de lo real (Lacan) que queda fuera de los modelos de mundo. La fotografía, al igual que ese pasaje de McCarthy, no te entrega ni al muerto ni la muerte, sino un modelo de mundo en que la muerte aparece figurada.

\section{Notas}

${ }^{1}$ Sobre la relación entre sintaxis y modelos de mundo véase Asensi (2015). Por otro lado, esta tesis no hace más que asumir un pensamiento que ya estaba delimitado en las teorías descoloniales (Franz Fanon es un buen ejemplo), el feminismo y los estudios de género (Teresa de Lauretis, Judith Butler, etc.). ${ }^{2}$ Las citas de Sein und Zeit proceden de tres fuentes, la versión española de Jorge Eduardo Rivera (2003), la inglesa de John Macquarrie y Edward Robinson (1962) y la versión original alemana de Heidegger (1927). Cuando la traducción o modificación es mía se explicita en el texto.Cuando la traducción es de algunos de los citados se indica la referencia de su traducción.

${ }^{3}$ La versión inglesa traduce Zeug por equipment y explica en nota al pie de página que dicha palabra no tiene un equivalente inglés preciso: "While it may mean any implement, instrument, or tool, Heidegger uses it for the most part as a collective noun which is analogous to our relatively specific "gear"” (Macquarrie y Robinson, 1962:97). La traducción española de «útil» nos parece adecuado siempre y cuando se tenga en cuenta el carácter de conjunto y de engranaje de los útiles.

${ }^{4}$ Empleo la noción de «estrategia narrativa» en el sentido que Paul de Man le da en su crítica de la lectura que Derrida hace de Rousseau (De Man, 1983:102-141).

${ }^{5}$ Las citas de esta novela se indican mediante el número de página de las ediciones inglesa y española que aparecen en la bibliografía.

${ }^{6}$ "Das Worin des sichverweisenden Verstehens als Woraufhin des Begegnenlassens von Seindem in der Seinsart der Bewandtnis ist das Phänomen der Welt» (Heidegger, 1927, 18: 86).

${ }^{7}$ En otro lugar Heidegger escribe: «El cuidado se convierte en búsqueda de las posibilidades de ver el "mundo" tan solo en su aspecto, reposando y demorando [junto a él]» (Rivera, 2003:190). 
${ }^{8}$ Es manifiesto que no puede darse por supuesto la equivalencia entre «sujeto» $\mathrm{y}$ «Dasein», a pesar de que entre la teoría lacaniana del «sujeto» (de la que partimos) y la concepción heideggeriana del «Dasein» hay más de un punto de contacto. Queda claro que en este texto se trata de aprovechar la teoría heideggeriana con el fin de plantear una determinada noción de mundo, y no tanto de respetarla.

\section{Referencias bibliográficas}

Althusser, L. (1969). Écrits. París: Garnier-Flammarion. Hay traducción parcial, que manejo aquí: Escritos, Barcelona, Laia, 1974. Es aquí donde se encuentra el ensayo «Ideología y aparatos ideológicos de Estado (Notas para una investigación)», pp. 105-170.

Asensi Pérez, M. (2011). Crítica y sabotaje. Barcelona: AnthroposSiglo XXI.

(2012). Los CSI y la guerra de Arguedas (en torno al silogismo del discurso en el pensamiento de la crítica como sabotaje). En Bolognese, C. et al. (Eds.), Este que ves engaño colorido... Literatura, culturas y sujetos alternos en América Latina (pp. 57-84). Barcelona: Icaria Editorial. (2013). Modelos de mundo y lectore/as desobedientes. Anthropos. Huellas del conocimiento, 237, 17-30.

(2015), Sintaxis y modelos de mundo. Valencia: Lynx, Documentos de trabajo, vol. 40 .

Bajtin, M. (1989). Teoría y estética de la novela. Madrid: Taurus.

AtutXa, I. (2014). Sabotajes de la cultura vasca: acerca de la nación encima del canon y hacia una nación-otra bajo tachadura (tesis doctoral). Universidad de Valencia, España.

De Man, P. (1983). The Rhetoric of Blindness. Jacques Derrida's Reading of Rousseau. En Blindness and Insihgt: Essays in the Rhetoric of Contemporary Criticism (pp. 102-141). Minneapolis: University of Minnesota Press.

Descartes, R. (1994 [1637]). Discurso del método. Madrid: Tecnos.

Ferrús, B. Zabalgoitia, M. (Coords.) (2013). La crítica como sabotaje de Manuel Asensi. Número monográfico de la revista Anthropos. Cuadernos de cultura crítica y conocimiento, (237).

Ferrús, B. y Poch, D. (2014). El español entre dos mundos: estudios de ELE en lengua y literature. Espańa: Iberoamericana, Vervuert.

Heidegger, M. (1953 [1927]). Sein und Zeit. Tübingen: Neomarius Verlag. LACAN, J. (ED.) (1987). Los cuatro conceptos fundamentales del psicoanálisis. El seminario, libro XI. Barcelona-México DF: Paidós. Ed. francesa: (1964), Le Séminaire de Jacques Lacan. Livre XI. Les quatre príncipes fondamentaux de la pshychanalyse. Paris: Seuil.

\section{Asensi Pérez, Manuel}

